\title{
THE EFFECTS OF ROOMING-IN CARE TO SUCCESSFUL BREASTFEEDING: A LITERATURE REVIEW
}

\author{
Anita Setyawati ${ }^{1}$, Restuning Widiasih ${ }^{2}$, Ermiati $^{3}$ \\ ${ }^{123}$ Faculty of Nursing, Universitas Padjadjaran, Bandung, Indonesia \\ Correspondence: anita.setyawati@unpad.ac.id
}

\begin{abstract}
Providing breast milk for a newborn is one method to reduce baby morbidity and mortality. "Baby-Friendly Hospital Initiative (BFHI)" is a program to support the practice of breastfeeding newborns in hospitals, one of them is by rooming in care, however not all hospitals do rooming-in care, including in Indonesia, and information about the effectiveness of rooming into successful breastfeeding is limited. This literature review was conducted to identify the effectiveness of rooming-in to encourage successful breastfeeding. The databases were CINAHL, and PubMed with keywords: breastfeeding, post-partum, baby, and rooming-in. There were eight articles that appropriate with the inclusion criteria. The results found that four of the six articles showed the effect a rooming-in on success breastfeeding, but two articles showed that there was no rooming-in effect on breastfeeding. Factors that influence the results of these studies include respondent demographic characteristics, health workers, family factor, and respondent's self-efficacy. Further research is needed specifically to examine the effectiveness of baby friendly hospital programs in Indonesia to breastfeeding management and to explore deeply about breastfeeding failure in rooming-in services.
\end{abstract}

Keywords: Baby, breastfeeding, mother, rooming-in, post-partum.

\section{INTRODUCTION}

Breast milk (ASI) is an ideal source of nutrition for newborns and also provides health benefits for mothers and children (Artieta-Pinedo et al., 2013). Epidemiological data showed that breast milk is better than formula for the infant (Stolzer \& Hossain, 2014). A cohort study comparing between the baby who obtained breast milk and formula found that babies with breast milk are less likely to suffer from eczema, gastrointestinal infections, respiratory infections, allergies, asthma, diarrhea, botulism, intestinal diseases, diabetes, liver disease, and sudden infant death syndrome (SIDS). Breast milk is the best food for babies.

The Indonesian government states that breastfeeding rates should increase as a way of reducing child and maternal morbidity and mortality in Indonesia (Ministry of Health Republic of Indonesia, 2011). According to The Surgeon General of The United States, the initiation of early breastfeeding (IMD), exclusive breastfeeding during the first six months, and breastfeeding for 2 years provide significant good health outcomes for baby (Stolzer \& 
Hossain, 2014). According to the published data, the target of achieving IMD, exclusive breastfeeding for the first six months, and breastfeeding for 2 years is under the World Health Organization (WHO) recommendation targets (Artieta-Pinedo et al., 2013). As a result, WHO launched the promotion of breastfeeding for baby as a priority scale in health programs in both developed and developing countries (Artieta-Pinedo et al., 2013; Brown \& Davies, 2014).

In 1991, WHO and The United Nations International Emergency Fund (UNICEF) launched "Baby-Friendly Hospital Initiative (BFHI)" to support the practice of proper feeding of newborns worldwide including Indonesia (V.A., H.K., \& M.S., 2015). The gold standard of BFHI is nursing care in hospitals (Tarrant et al., 2011). BFHI describes 10 steps that the hospital must follow to get Baby-Friendy Hospital status. One step that must be carried out by the hospital is Rooming-in mothers and babies (WHO, UNICEF, \& Wellstart International, 2009). However, not all hospitals provide rooming in services for postpartum women and their babies, including in Indonesia. In addition, there is still limited information on rooming in effectiveness for breastfeeding success. This literature review was conducted to determine the effectiveness of rooming in successful breastfeeding.

\section{METHODS}

The literature review is arranged in several stages, including article search, article selection, and analysis. The source of the article is a systematic and computerized database, which are Cinahl and PubMed, with search keywords were breastfeeding, mother, baby or newborn, rooming-in, and postpartum. The author screened articles with inclusion criteria, including: (1) articles published from 2008 - 2018, (2) articles using English, (3) articles containing content about the effectiveness of rooming in the success of breastfeeding. Based on the screening process, six articles are described in table 1. 


\section{RESULT}

Table 1. The Effectiveness Rooming-in to Encourage Successful Breastfeeding

\begin{tabular}{|c|c|}
\hline Authors & Methods \\
\hline $\begin{array}{l}\text { (Chiou, Chen, } \\
\text { Yeh, Wu, \& } \\
\text { Chien, 2014) }\end{array}$ & $\begin{array}{l}\text { Respondents were 12,201 postpartum } \\
\text { mothers in } 2004 \text { and } 12,405 \\
\text { postpartum mothers in 2011. Data } \\
\text { collection was done by telephone } \\
\text { interviews using a structured } \\
\text { questionnaire about their breastfeeding }\end{array}$ \\
\hline & $\begin{array}{l}\text { experiences when they were } \\
\text { hospitalized }\end{array}$ \\
\hline
\end{tabular}

Results

The results of this study indicated that more postpartum mothers who did early skin-to-skin contact in 2011 compared to 2004 (33.8\% vs $20.6 \%, \mathrm{p}<0.001)$. The results also revealed that the comparison of the number of postpartum mothers who did rooming-in in 2011 was less than in 2004 (33.8\% vs $20.6 \%, p<0.001)$. However, the percentage of postpartum mothers who did rooming-in for 24 hours between 2004 and 2011 increased. In addition, this study also showed that breastfeeding rates from 2004 to 2011 have increased. During the hospitalization, the rate of breastfeeding increased by $50 \%$. While during the six months postpartum the rate of breastfeeding increased by $150 \%$

(Tarrant et al., Respondents were 1,242 pairs of 2011)

(Stage,

Mathiesen, Emmersen, Greisen, Damm, 2010)

(Bystrova et al., 2009)

(Zuppa et al., This study involved 903 newborns. The 2009) mothers and infants that were monitored prospectively for 12 months. In the hospital, mothers and infants were directed to do six Baby-Friendly Program practices including roomingin.

This study compared old cohort records of 103 infants in The Neonatal Special Care Unit (NSCU) of diabetic mothers \& and a new cohort record of 102 infants who were rooming with their mothers who had diabetes.

Respondents were 176 pairs of mothers and infants grouped into four groups. I, infants with IMD and roomed-in. II, babies who wear clothes are placed on the arms of their mothers after birth and roomed-in with their mothers in the maternity ward. III, newborns, and their mothers were separated in the baby's room and the maternity ward. IV, the newborn was in the baby's room and continued to be roomed-in with his mother. The success of "nearly exclusive breastfeeding" was recorded for one year after birth.

purpose of this study was to compare the effect of partial rooming-in and full rooming-in on exclusive breastfeeding after mothers and baby had discharged from the hospital.
The results of this study indicated that $46.6 \%$ of mothers breastfeed their baby more than eight weeks and $4.8 \%$ of mothers did the six BabyFriendly Program practices. The results also revealed that mothers who did six Baby-Friendly Program practices including rooming in had likely three times possibility to continue breastfeeding after being discharged from the hospital

The results of this study indicated that babies who were rooming-in with their mothers obtained breast milk more often than babies who were separated from their mothers. Neonatal morbidity and neonatal because of hypoglycemia of the rooming-in group with were less compared to the group of babies who were separated from their mothers

The results showed that there was no significant difference in "nearly exclusive breastfeeding" between the four groups $(p=0.12)$. However, mothers in groups I and II could immediately breastfeed their babies in the first two hours after birth in the delivery room. The median time of "nearly exclusive breastfeeding in the four groups was four months in the first group (range 0.5-12 months); 3.5 months in the second group (range 1 week - 11 months); four months in the third group (range 1 week - 12 months); lastly, five months in the fourth group (range 1 week - 12 months)

The results showed that the percentage of exclusive breastfeeding after discharge from the full rooming-in group was $80 \%$ while the partial rooming-in group was $42.9 \%$. 


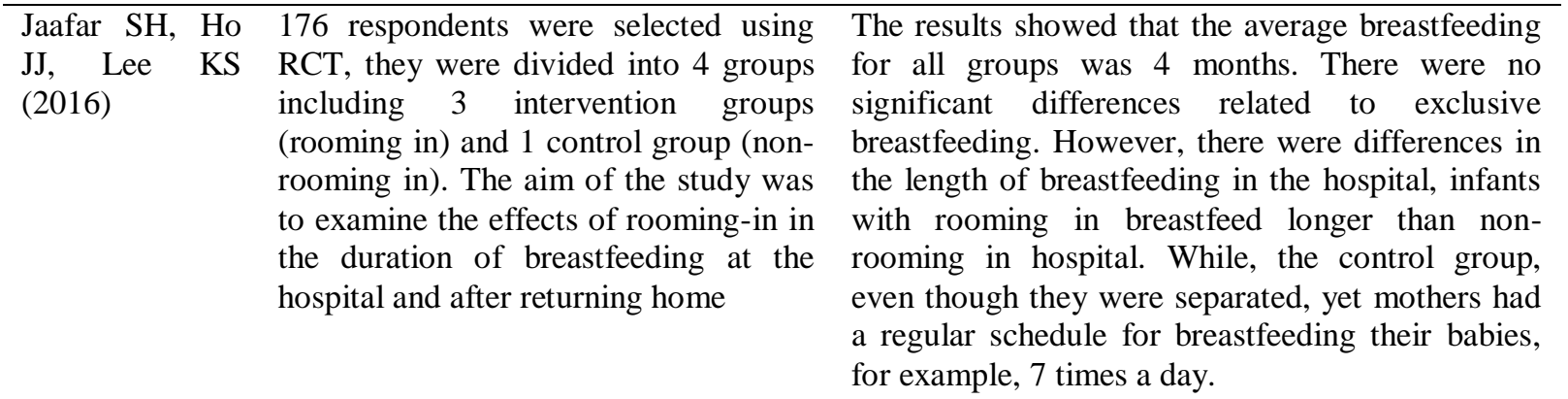

\section{DISCUSSION}

The results of the analysis showed that four out six articles reported the effect of rooming-in care to successful breastfeeding (Chiou et al., 2014; Tarrant et al., 2011; Stage et al., 2010; Zuppa et al., 2009). However, other two studies found there were no significant differences of breastfeeding of respondents with rooming-in care and separated care (Bystrova et al., 2009; Jaafar SH, Ho JJ, Lee KS, 2016). Research conducted in Taiwan proved that rooming-in for more than 12 hours was associated with an increase in exclusive breastfeeding during the six months postpartum (Chiou et al., 2014). The results of this study may be influenced by the regulation of the Taiwan government regarding the promotion of breastfeeding which includes campaigns on mass media, training for health workers in hospitals, applying 10 steps of Baby-Friendly Hospital, establishing breastfeeding support groups, and accreditation at Baby-Friendly Hospital. Policies and practices of breastfeeding in Baby-Friendly Hospitals in Taiwan contribute have increased to successful breastfeeding. Mothers who gave birth in Baby-Friendly Hospitals had higher rates of breastfeeding compared to mothers who gave birth in non-accredited Baby-Friendly Hospital. The hospital with the Baby-Friendly hospital program was also developed by the Indonesian government, but there was limited research on the effectiveness of the program on the success of breastfeeding both IMD, exclusive breastfeeding, and breastfeeding babies up to 2 years. 
Anita Setyawati: The Effects of Rooming-in Care to Successful Breastfeeding

The results of research in Hong Kong showed that there was a relationship between the practice of Baby-Friendly Hospital and breastfeeding (Tarrant et al., 2011). Mothers who exclusively breastfeed while in the hospital and carry out Baby-Friendly Hospital practices have a low level of stopping breastfeeding. While mothers who did not give exclusive breastfeeding while in the hospital and did not practice Baby-Friendly Hospital had the possibility three to four times the cessation of breastfeeding early.

A study in Denmark revealed that rooming-in mothers who have type 1 diabetes with their babies had a positive effect on newborns' health (Stage et al., 2010). In addition, rooming-in in this study also found a low level of morbidity in infants. Newborns from mothers with type 1 diabetes commonly showed hyperinsulinemia immediately after birth. However, in infants who were immediately initiated early breastfeeding, the risk of hyperinsulinemia was minimal.

This literature review also found that two out of six articles showed that there was no significant difference in breastfeeding between rooming-in and non-rooming-in groups (Bystrova et al., 2009). Research in Russia showed that there was no rooming-in effect on success breastfeeding (Bystrova et al., 2009). This may because of the exclusive breastfeeding was not a common practice or program in Russia. In addition, Jaafar SH, Ho JJ, \& Lee KS (2016) study showed that the average breastfeeding for all groups was 4 months both intervention and control groups (non-rooming-in group). This happened because of the control group had a regular schedule to breastfeed their babies, and they were breastfeeding according to the set schedule, so even though they were separated, mothers had visited their babies regularly into the baby's room for breastfeeding. Furthermore, understanding about breastfeeding management would be affected by mothers' attitude related to IMD, exclusive breastfeeding, and breastfeed their babies until two years. The attitude would also influence their breastfeeding behavior. The good understanding of breastfeeding knowledge and 
positive attitude towards breastfeeding would increase the length of breastfeeding and exclusive breastfeeding. Both health services factors including rooming-in care and individual factors such as mothers' knowledge are significant to successful breastfeeding.

\section{CONCLUSION}

According to this literature review, it can be concluded that the majority of the literature shows that rooming-in care is significant for the success of breastfeeding. In addition, rooming-in is also increasing maternal knowledge about the management of breastfeeding. Rooming-in care would reduce the level of morbidity in mothers with conditions of illness (diabetes) or infants with unhealthy conditions (jaundice). This literature also informs that separate care can also carry out breastfeeding optimally, health workers help mothers by scheduling and facilitating them to visit and breastfeed their babies regularly, and mothers are willing to follow the schedule. The future study should investigate the effectiveness of baby friendly hospital programs in Indonesia to breastfeeding management including IMD, Exclusive breastfeeding, breastfeed their babies until two years, and another future research that aims to explore deeply about breastfeeding failure in rooming-in services.

\section{REFERENCES}

Artieta-Pinedo, I., Paz-Pascual, C., Grandes, G., Bacigalupe, A., Payo, J., \& Montoya, I. (2013). Antenatal Education and Breastfeeding in a Cohort of Primiparas. Journal of Advanced Nursing, 69(7), 1607-1617. https://doi.org/10.1111/jan.12022.

Brown, A., \& Davies, R. (2014). Fathers' Experiences of Supporting Breastfeeding: Challenges for Breastfeeding Promotion and Education. Maternal and Child Nutrition, 10(4), 510-526. https://doi.org/10.1111/mcn.12129.

Bystrova, K., Ivanova, V., Edhborg, M., Matthiesen, A.-S., Ransjo-Arvidson, A. B., Mukhamedrakhimov, R., ... Widstrom, A. M. (2009). Early Contact Versus Separation: Effects on Mother-Infant Interaction One Year Later. Birth, 36(2), 97-109. https://doi.org/10.1111/j.1523-536X.2009.00307.x.

Chiou, S. T., Chen, L. C., Yeh, H., Wu, S. R., \& Chien, L. Y. (2014). Early Skin-to-Skin 
Contact, Rooming-in, and Breastfeeding: A Comparison of the 2004 and 2011 National Surveys in Taiwan. Birth, 41(1), 33-38. https://doi.org/10.1111/birt.12090.

KementrianKesehatanRepublikIndonesia. (2011). Refleksi Hari Ibu: Skenario Percepatan Penurunan Angka Kematian Ibu. Retrieved from

http://www.kesehatanibu.depkes.go.id/archives/335.

Lin, C. H., Kuo, S. C., Lin, K. C., \& Chang, T. Y. (2008). Evaluating Effects of A Prenatal Breastfeeding Education Programme on Women with Caesarean Delivery in Taiwan. Journal of Clinical Nursing, 17(21), 2838-2845. https://doi.org/10.1111/j.13652702.2008.02289.x.

Mohite, R. V., Mohite, V. R., \& Kakade, S. V. (2012). Knowledge of Breastfeeding among Primigravida Mothers. Bangladesh Journal of Medical Science, 11(4), 312-316. https://doi.org/10.3329/bjms.v11i4.12603.

Stage, E., Mathiesen, E. R., Emmersen, P. B., Greisen, G., \& Damm, P. (2010). Diabetic Mothers and Their Newborn Infants - Rooming-in and Neonatal Morbidity. Acta Paediatrica, International Journal of Paediatrics, 99(7), 997-999. https://doi.org/10.1111/j.1651-2227.2010.01779.x.

Stolzer, J. M., \& Hossain, S. A. (2014). Breastfeeding Education: A Physician and Patient Assessment. Child Development Research, 2014, 1-6. https://doi.org/http://dx.doi.org/10.1155/2014/413053 Research.

Tarrant, M., Wu, K. M., Fong, D. Y. T., Lee, I. L. Y., Wong, E. M. Y., Sham, A., ... Dodgson, J. E. (2011). Impact of Baby-Friendly Hospital Practices on Breastfeeding in Hong Kong. Birth: Issues in Perinatal Care, 38(3), 238-245. https://doi.org/10.1111/j.1523-536X.2011.00483.x.

V.A., K., H.K., R. W., \& M.S., M. (2015). Awareness about "Ten Steps for Successful Breastfeeding" among Medical and Nursing Students. International Journal of Preventive Medicine, 6(40), no pagination. https://doi.org/10.4103/2008-7802.156838.

WHO, UNICEF, \& Wellstart International. (2009). Baby-Friendly Hospital Initiative : Revised, Updated and Expanded for Integrated Care. Section 3, Breastfeeding Promotion and Support in A Baby-Friendly Hospital: A 20-Hour Course for Maternity Staff. Geneva: WHO Document Production Services. https://doi.org/ISBN 978924 1594967 (v. 1).

Zuppa, A. A., Sindico, P., Antichi, E., Carducci, C., Alighieri, G., Cardiello, V., ... Romagnoli, C. (2009). Weight Loss and Jaundice in Healthy Term Newborns in Partial and Full Rooming-in. The Journal of Maternal-Fetal \& Neonatal Medicine: The Official Journal of The European Association of Perinatal Medicine, the Federation of Asia and Oceania Perinatal Societies, the International Society of Perinatal Obstetricians, 22(9), 801-805. https://doi.org/10.3109/14767050902994499 